\title{
Study Physicochemical of the Raw Palm Oils of the Republic of Gabon and Congo
}

\author{
Hugues Romuald Pamba Boundena ${ }^{1,2^{*}}$, Raphaël Bikanga ${ }^{1}$,Thomas Silou ${ }^{2}$
}

\author{
${ }^{1}$ Laboratoire de Chimie des Substances Naturelles et Synthèses, Faculté des Sciences, Université des Sciences et Techniques \\ de Masuku (FS/USTM), BP: 941, Franceville - Gabon \\ ${ }^{2}$ Laboratoire du Pôle d'Excellence Régional (AUF) en "Alimentation et Nutrition”, Equipe Pluridisciplinaire de Recherche \\ en Alimentation et Nutrition (E.P.R.A.N.), BP: 389 Brazzaville - Congo \\ *Correspondant : hugues_pamba@yahoo.com
}

\begin{abstract}
The palm oil exists in several forms: palm oil raw, not refined, of red color because very rich carotenoids, called «red palm oil». In Africa, it is generally sold and consumed rough, i.e. not having undergoes the stages of refining. Taking into account the quantity and relevance of existing work on the palm tree with oil, we limited our study of Elaeis guinensis of Congo Basin to the analysis of the oils taken on the ground of the natural palm plantations and of the plantations of the palm plantation of M'vouna (Gabon) and of the Rural Campus of Loukoko (Congo) the study of our samples reveals the presence of carotenoids between 400 and $480 \mathrm{~nm}$, and the presence of the chlorophyllian pigments with 600 and $670 \mathrm{~nm}$ for the great number of analyzed spectra. In the palm oil, the contents of carotenoids extend between 400 and $480 \mathrm{~nm}$. The total content carotenoids varies from 897,1 $\mu \mathrm{g} / \mathrm{ml}$ with 1229,3 $\mu \mathrm{g} / \mathrm{ml}$ for the samples of the Palm plantation of M'vouna (Franceville, Gabon), whereas for the samples of Loukoko (Congo) that varies from 583,1 $\mu \mathrm{g} / \mathrm{ml}$ with $1110,5 \mu \mathrm{g} / \mathrm{ml}$ on average. During precipitation partial of the raw palm oils of Gabon, three cases of figure ariseed (progressive, brutal and null solidification). The content total polyphenols varies from 439 to $2516 \mu \mathrm{g} / \mathrm{ml}$. Of all the analyzed samples, the sample of Congo contains the maximum of phenolic compounds $(2516 \mu \mathrm{g} / \mathrm{ml})$. Minimum of $439 \mu \mathrm{g} / \mathrm{ml}$, being obtained on the sample of Gabon. Their high content in carotenoids, fatty-acid unsaturates and the strong content total polyphenols, make our different oils more beneficial as well in the nutritional plan as therapeutic. The objective of work is the physicochemical characterization of the raw palm oils of the Republic of Gabon and Congo. The physicochemical characteristics of these oils are given according to the conventional normalized methods. They are the analyzes such as the spectroscopic evaluation of the color, the content carotene, partial solidification and the content polyphenols.
\end{abstract}

Keywords- raw palm oils, color, carotene, solidification, polyphenols, Gabon, Congo.

\section{INTRODUCTION}

Palm oil of Gabon east very appraisal in central Africa in particular in Cameroun. To our knowledge, the data on the palm oils are not complete, and there do not exist comparative studies carried out on the physicochemical properties of these artisanal raw palm oils in Gabon, in comparison with "traditional" oils more. This lack of data seems to be a handicap for the valorization of these oilseeds which could have food potentials of applications, cosmetic and energy, which remains unfortunately underexploited. In this work, one will compare the physicochemical characteristics of oils of the raw palm oils of Gabon with those of oils of Congo of everyday consumption (nut oil of palm) for a better valorization in the human consumption and to arouse his interest.

The study of the absorption spectrum of an oil in the visible one makes it possible to determine the maximum wavelengths giving an indication on the pigments which are dissouts there.

The color of the palm oil is primarily related to the presence of carotenoids and chlorophyls. In the palm oil, the contents of carotenoids extend between 400 and 480 nm.

The composition and the total content of the pigments naturally present in oil, are important parameters because they are correlated with the color, which is a basic attribute to evaluate the quality of palm oil. The pigments are also implied in the mechanisms of self-oxidation and the photo-oxidation. Their presence in the palm oil is detected in a band which extends between 600 and 670 ppm for chlorophyls. With the light, chlorophyl supports the formation of the radicals of oxygen and accelerates oxidation but in the darkness, chlorophyl acts as an antioxydant.

Chlorophyl is a chlorine (four cores pyrroles in circle), chelating a magnesium atom in the center, as well as an alcohol with long chain, phytol. It has a structure comparable with that of heme (present in the blood red globules). It is the presence, in its structure, of many doubles combined connections which allows an 
absorption of the light radiation. The side chains of chlorine are variable and this involves a modification of the absorption spectrum between the various families of chlorophyls (Hartmut and Lichtnetharler, 1987).

The name "carotene" is derived from the root of carrot (Daucus carota), which was insulated like pigment coloured in 1831 (Tan, 1988). Roughly, the majority of 500 known carotenoids are naturally coloured (example tonalities yellow-orange-reds), and nearly about fifty these dyes have the activity of the vitamin has with various degrees.

Chemically, the carotenoids are combined hydrocarbons being able to be classified like carotenes (absence of oxygen atoms) or xanthophylls (presence of several oxygen atoms). The palm oil contains the highest concentration of the carotenoids agro-derivatives. The content carotenoids of the raw palm oil is of $500-2000$ $\mathrm{Mg} / \mathrm{kg}$ whereas other raw plant oils contain of them approximately $100 \mathrm{mg} / \mathrm{kg}$ (Lecerf, 2013).

The melting solubility and point constitute the two principal physical properties of the lipids. The distinction between oils and greases rests on their melting point. Oils are liquid greasy substances at the temperature of $15^{\circ} \mathrm{C}$, while greases are more or less solid at this temperature (they are known as also "concrete"). Such a distinction can however lead to a certain ambiguity: the same greasy substance being able to be fluid or concrete according to the value of the room temperature of the country considered. It is of however certain interest to the nutritional plan, insofar as greases contain more saturated fatty-acids than oils (FAO/OMS, 1977).

The greasy substances being essentially made up of triglycerides, their temperature of solidification will be mainly function of their composition in fatty-acids.

Studies showed that the simple phenols and the phenolic acids, like the flavonoïdes, play a key role in the elimination and the detoxification of the free radicals, and make it possible to increase the resistance of the LDL (Low Density Lipoproteins) oxidation and to inhibit the peroxidation of the lipids (Decker, 1995; Visioli et al., 1995). The content of phenolic compounds of the palm oil is function of the variety of nuts, of their maturity at the time of harvest, the environment and the conditions of treatment.

\section{MATERIAL AND METHODS}

\subsection{MATERIAL}

The vegetable material consists of nut of palm and raw palm oil.

The study related to samples of palm oils collected on the ground to Gabon and Congo. These samples come from six (06) provinces of Gabon. The economic capital (PortGentil, in maritime Ogooue), was from the isolated start of the investigation, because considered as a place of flow of the production and not of manufacture. The investigation was not made either in the provinces of Nyanga and Ngounie, provinces too far away from the site of the University of Sciences and Technology of Masuku (USTM) and especially of difficult access. The investigation in Congo related to the town of Brazzaville and the area of the Pool, considered as the attic of the country.

It is thus in the Estuary (Libreville, N'Toum and Cocobeach), Haut-Ogooue (Palm plantation of association M'Vouna, Djamiti, Franceville); the Means-Ogooue (associations Nkolo of Atongowanga, Lambarene and Nyngone Georgette de Faisceaux, Lambarene); Ogooue Ivindo (Makokou); Ogooue Milk (Koula-Moutou) and Woleu-Ntem (Oyem), which we carried out of the investigations. The palm oils analyzed within the framework of this work all are extracted artisanalement and artisanalement stored with room temperature.

In Congo, the investigation was focused on the households of the town of Brazzaville and the palm plantation of the Rural Campus of Loukoko (RCL), in the area of the Pool.

\subsection{METHODS}

For the physicochemical characteristics of oils, the spectroscopic evaluation, partial solidification were given according to the normalized methods (AFNOR, 1981; IUPAC, 1979). The evaluation of the content total carotenoids and total chlorophyls, and the content polyphenols were made according to the method described by (Benabid, 2009).

\section{Spectroscopic evaluation of the color}

Into a graduated flask of $10 \mathrm{ml}$, one introduces $0,1 \mathrm{~g}$ of beforehand melted grease with $50^{\circ} \mathrm{C}$ and one supplements with chloroform to the feature of gauge. One measures then absorption, using a spectrophotometer of the type GENESYS 10 Bio (Photo 1), between 400 and $750 \mathrm{~nm}$. The maximum ones of absorption for carotenoids are: 400,425,455 and $480 \mathrm{~nm}$, and for chlorophyls: 600 and $670 \mathrm{~nm}$, which are the principal pigments of plant oils.

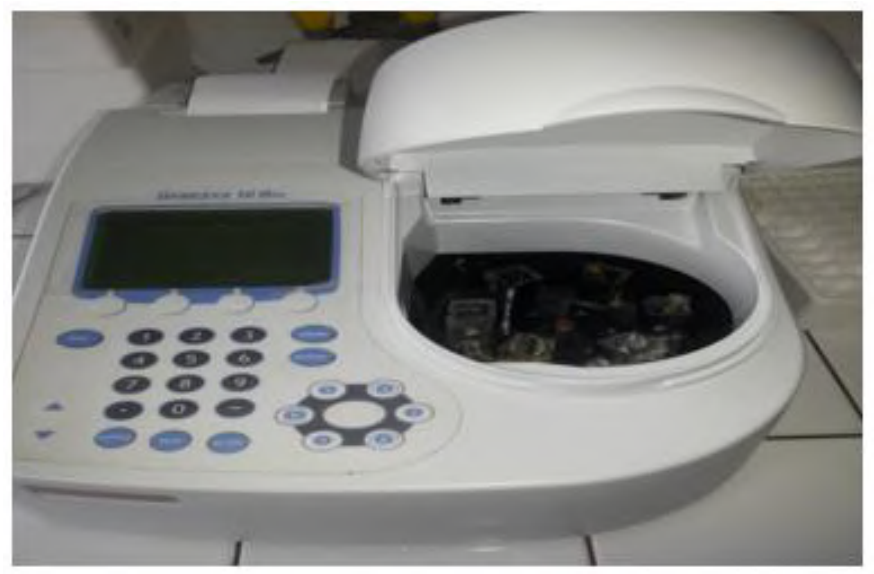

Photograph 1: spectrophotometer of the type GENESYS 10 Bio 


\section{Content carotene}

The total carotenoids were determined by spectrophotometry UV with the wavelengths ranging between 400 to $760 \mathrm{~nm}$.

The calculation of the content carotene in the palm oil, was carried out starting from the Optical Density (OD) with $460 \mathrm{~nm}$ according to:

$\mathrm{Y}=0,0775 \mathrm{x}+0,0029$

$$
\mathrm{X}=\frac{y-0,0029}{0,0775} \text { with } \mathrm{X} \text { : content carotene and } \mathrm{Y} \text { : }
$$

represent the Optical Density

The identification of the content of carotenoids was carried out by considering the reading of the Optical Densities (OD) with $460 \mathrm{~nm}$ and the equation:

$\%$ carotenoid $=4,57$ OD $\left(\mathrm{R}^{2}=0.989\right)$ (Davis and Al, 2009).

\section{Partial solidification}

Into a test-tube of $50 \mathrm{ml}$, one introduces $20 \mathrm{ml}$ of oil of the fat contents, heated beforehand by the drying oven at the temperature of $70^{\circ} \mathrm{C}$. In the course of time, the quantity of oil having precipitated (in $\mathrm{ml}$ ) is raised.

Proportioning of polyphenols
The total polyphenols are proportioned thanks to their capacity to reduce the acids phosphotungstic and phosphomolybdic, contents in the reagent of Folin, out of oxides of tungstens and molybdenum. The latter present a bluish coloring, measured with $760 \mathrm{~nm}$.

$200 \mu \mathrm{l}(0,2 \mathrm{ml})$ of oil is added to $400 \mu \mathrm{L}(0,4 \mathrm{ml})$ of a mixture water-methanol $(25: 75 ; \mathrm{v} / \mathrm{v})$. The unit is placed at the vortex during 1 minute in order to extract polyphenols in the medium methanolic. One adds then $200 \mu \mathrm{l}(0,2 \mathrm{ml})$ of dichlorométhane, to allow the oily phase to become more; the goal is to facilitate the collection of $200 \mu \mathrm{l}$ of supernatant methanolic. $800 \mu \mathrm{l}$ of reagent of Folin diluted 10 times in water is then added and it mixture is left 2 minutes to the room temperature before addition of $1 \mathrm{ml}$ of sodium carbonate $(75 \mathrm{~g} / \mathrm{L})$. This last mixture is heated $15 \mathrm{~min}$ with $50^{\circ} \mathrm{C}$ then analyzed to $760 \mathrm{~nm}$ (Benabid, 2009).

The external calibration of the gallic acid uses the reagent of Folin $(4 \mathrm{~mL})$, a sodium carbonate solution $(5 \mathrm{~mL})$ and a solution mother, consisted of the methanol-water mixture and gallic acid.

Table.1: hereafter defines the various proportions of the calibration of the gallic acid:

\begin{tabular}{cccc}
\hline $\begin{array}{c}\text { Not range } \\
(\mathbf{m g} / \mathbf{L})\end{array}$ & $\begin{array}{c}\text { Reagent of Folin } \\
(\mathbf{m L})\end{array}$ & $\begin{array}{c}\text { Sodium carbonate } \\
(\mathbf{m L})\end{array}$ & $\begin{array}{c}\text { Solution Mother } \\
(\mathbf{m i x} \text { methanol-water and gallic acid) } \\
(\mathbf{v}: \mathbf{v}) \mathbf{~ e n ~} \mathbf{~ m L}\end{array}$ \\
\hline 0 & 4 & 5 & $(1: 0)$ \\
\hline 50 & 4 & 5 & $(0,1: 0,9)$ \\
\hline 100 & 4 & 5 & $(0,2: 0,8)$ \\
\hline 250 & 4 & 5 & $(0,5: 0,5)$ \\
\hline 500 & 4 & 5 & $(0: 1)$ \\
\hline
\end{tabular}

\section{Content polyphenols}

The content of total polyphenols was given starting from the calibration curve (figure 1) of the gallic acid.

The calculation of the content polyphenol in the palm oil starting from OD with $450 \mathrm{~nm}$ was carried out in the following way:

$\mathrm{Y}=0,0051 \mathrm{x}+0,0492$

$\mathrm{X}=\frac{y-0,0492}{0,0051}$ with $\mathrm{X}$ : content polyphenol and $\mathrm{y}$ : represent the optical density

\section{RESULTS AND DISCUSSION}

Physicochemical characteristics of the oils studied by various methods (AFNOR, 1981; IUPAC, 1979) gave the following results:
Spectroscopic evaluation of the color

The majority chlorophyllian pigments in oils of green coloring and carotenoids majority in oils of red/yellow coloring absorb in the visible one between 400 and 700 nm (Silou et al., 2004).

The measurement of absorption in this zone informs about the intensity of the color of oil or studied grease. This intensity is, in theory proportional to the quantity of pigments present in oil, when the law of Beer-Lambert is followed.

The palm oils of Gabon have identical spectra (figures 1) and present peaks between 425 and $480 \mathrm{~nm}$, which reveal the presence of carotenoids. 


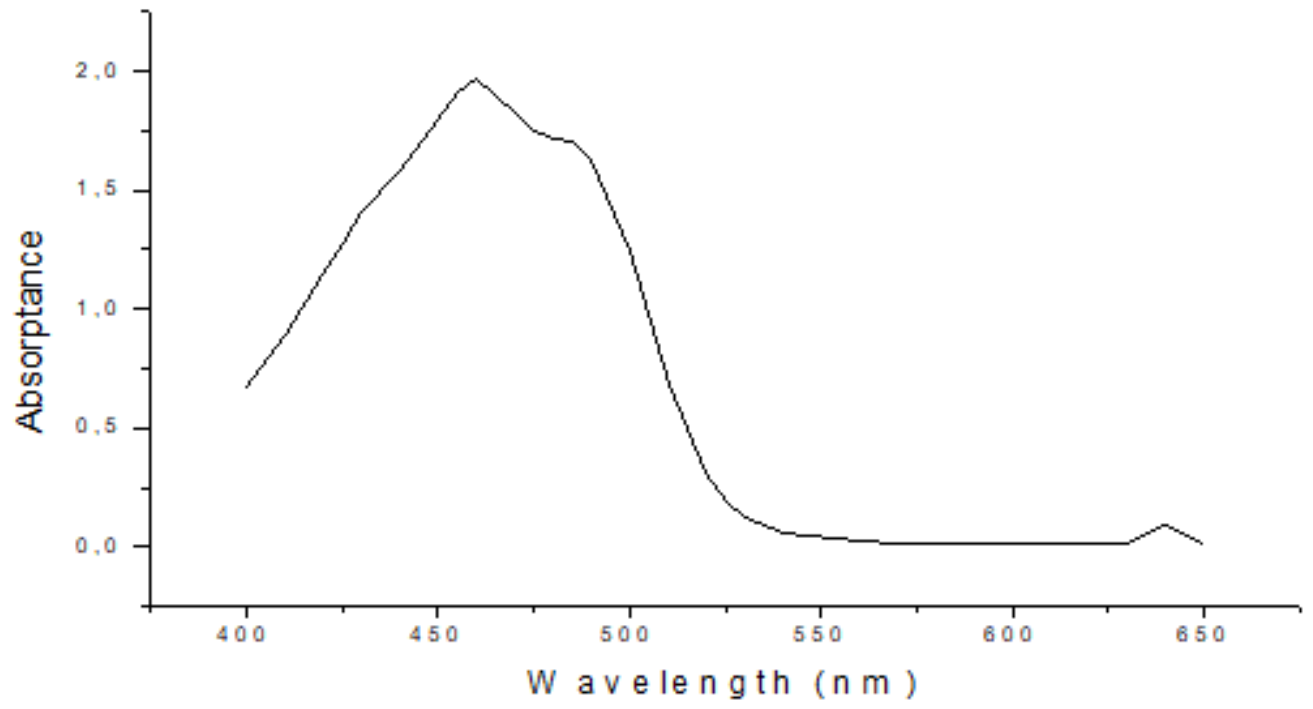

Fig.1: Curve of absorption in the visible of the HPR2 M'vouna (Gabon)

It is noted that the eight palm oil samples of Loukoko have similar spectra(figures 2), showing distinctive peaks which also reveal the presence of carotenoids. They are in conformity with those met in the literature for plant oils (Helmy, 1990). It is also noted that all these eight absorption spectra take the same form. All this intuitively enables us to suggest the same hierarchy in the intensity of the color perceived for the samples of Loukoko taken in 2013 what confirms well the not distinctive observation from point of view of the coloring of oils of this area. However, not being able to conclude with the absence from the chlorophyllian pigments in these oils from Gabon and Loukoko (2013), we put forth the assumption that the pigments are there with the state of traces.

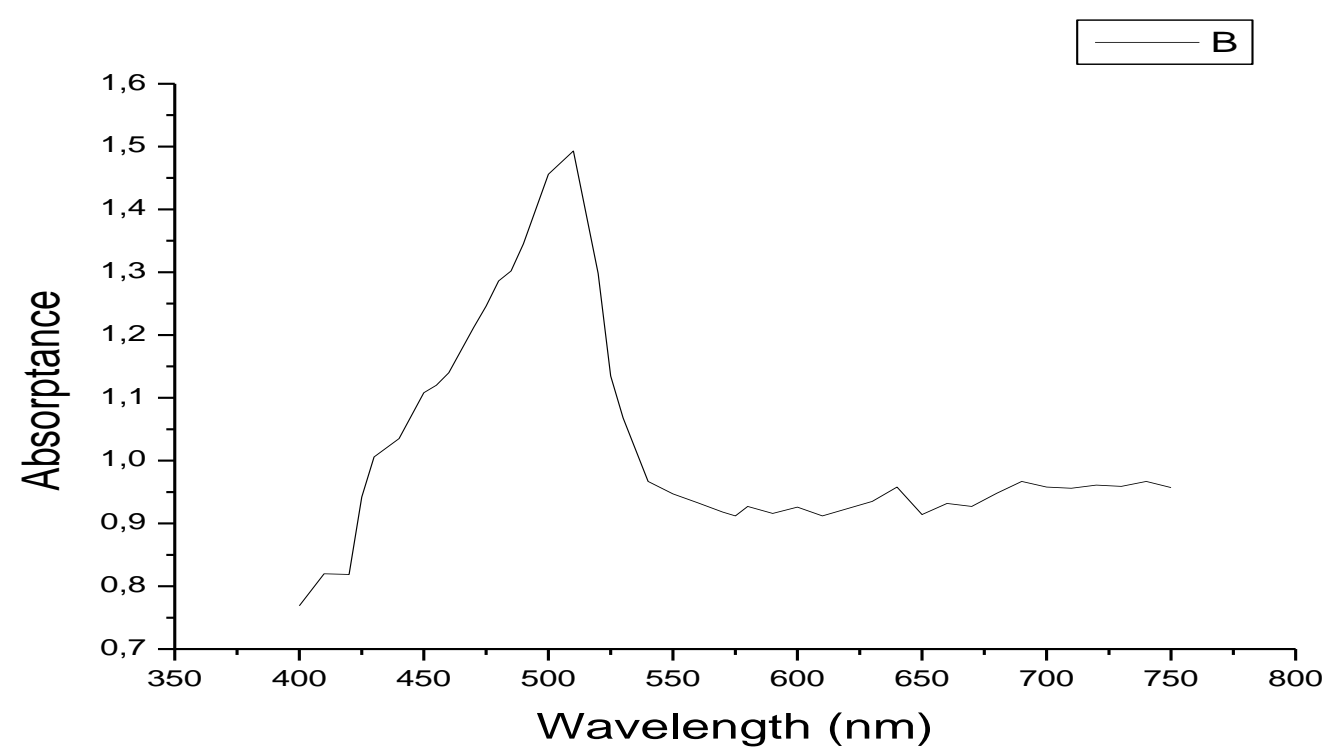

Fig.2: Curve of absorption in the visible ofHP 05/14 Loukoko (Congo)

It is noted that the five palm oil samples of Loukoko have spectra different from those of 2013.By studying the oils extracted from seeds of citrus and cucurbitaceous, Helmy (1990) identified the maximum ones of absorption with 400,425,455 and $480 \mathrm{~nm}$ for carotenoids, 600 and $670 \mathrm{~nm}$ for chlorophyls. The examination of these spectra shows distinctive peaks which reveal the presence of carotenoids between 400 and $480 \mathrm{~nm}$, and the presence of the chlorophyllian pigments with 600 and $670 \mathrm{~nm}$ for these five spectra.

\section{Content carotene}


The content carotene was calculated starting from the equation:

$\%$ carotenoid $=4,57$ OD $(\mathrm{R} 2=0,989)($ Davis and Al, 2009).

The calculation of the content carotene in the palm oil starting from $\mathrm{C}$ with $460 \mathrm{Nm}$ was carried out in the following way:

$\%$ carotenoid $=4,57$ OD $(\mathrm{R} 2=0,989)$.

$\mathrm{Q} 2(10 \mathrm{ml})=\mathrm{C} 2 \times 10=\mathrm{C} 1$

$\mathrm{Q} 2(10 \mathrm{ml})=\mathrm{C} 2 \times 10$, it is the quantity contained in $1 \mathrm{ml}$ of the solution $\mathrm{S}$.

$\mathrm{Q} 1(10 \mathrm{ml})=\mathrm{C} 1 \mathrm{X} 10$, it is the quantity contained in $1 \mathrm{ml}$ of starting oil.

With:

$\mathrm{C} 1$ : concentration of carotenes in the starting oil, in $\mu \mathrm{g} / \mathrm{mL}$ or $\mathrm{ppm}$

C2: concentration of carotenes in $\mathrm{S}$ (solution), in $\mu \mathrm{g} / \mathrm{mL}$ or ppm

Q1: quantity of carotenes in $\mu \mathrm{g}$ in the starting oil

Q2: quantity of carotenes in $\mu \mathrm{g}$ in $\mathrm{S} 1$

Application: case of the oil of the palm plantation of M'vouna (HPR 1 M'vouna)

$\mathrm{C} 2=4,57 \mathrm{X}$ OD
$\mathrm{C} 2=4,57 \times 2,547=11,64 \mu \mathrm{g} / \mathrm{mL}$

Q2 $(10 \mathrm{ml})=11,64 \times 10=116,4 \mu \mathrm{g}$, it is the quantity contained in $1 \mathrm{ml}$ of solution $\mathrm{S}$.

Q1 $(10 \mathrm{ml})=116,4 \times 10=1164 \mu \mathrm{g}$ it is the quantity contained in $1 \mathrm{ml}$ of starting oil.

Content carotenoids (HPR1 Palm plantation of M'vouna)

$=1164 \mu \mathrm{g} / \mathrm{ml}$

This returns 11,64 X 100 i.e. C2 X 100

The calculation of the content carotene in the palm oil starting from OD with $460 \mathrm{Nm}$ was carried out in the following way:

$\mathrm{Y}=0,0775 \mathrm{x}+0,0029$

$\mathrm{X}=(\mathrm{y}-0,0029) / 0,0775$ with $\mathrm{X}$ : content carotene and there: represent the Optical Density (OD)

The total content carotenoids varies from $897,1 \mu \mathrm{g} / \mathrm{ml}$ (HPR2) with 1229,3 $\mu \mathrm{g} / \mathrm{ml}$ (HPR5) for the samples of the Palm plantation of M'vouna (Franceville, Gabon), of $574,9 \mu \mathrm{g} / \mathrm{ml}$ (HP3) with 1330,8 $\mu \mathrm{g} / \mathrm{ml}$ (HP6) for the samples of Lambarene (Gabon), whereas for the samples of Oyem it is of $878,4 \mu \mathrm{g} / \mathrm{mL}$ (HP 9) and $1190,9 \mu \mathrm{g} / \mathrm{mL}$ (HP 10) and finally for the samples of Loukoko (2013) that on average varies from 583,1 $\mu \mathrm{g} / \mathrm{ml}$ (HPR 2/13/L) with $1110,5 \mu \mathrm{g} / \mathrm{ml}$ (HPR 9/13/L) (table A).

Table.A: Content carotene of the samples of Gabon and Loukoko (Congo)

\begin{tabular}{lccc}
\hline \multicolumn{1}{c}{ References } & OD & C2 $(\boldsymbol{\mu g} / \mathbf{m L})$ & $\begin{array}{c}\text { Content carotenoid } \mathbf{~ p p m ~} \\
(\boldsymbol{\mu g} / \mathbf{m L})\end{array}$ \\
\hline HPR 1 M'vouna & 2,547 & 11,640 & 1164 \\
\hline HPR 2 M'vouna & 1,963 & 8,971 & 897,1 \\
\hline HPR 4 M'vouna & 2,161 & 9,876 & 987,6 \\
\hline HPR 5 M'vouna & 2,690 & 12,293 & 1229,3 \\
\hline HP 3 Lambarene & 1,258 & 5,749 & 574,9 \\
\hline HP 4 Lambarene & 2,416 & 11,041 & 1104,1 \\
\hline HP 6 Lambarene & 2,912 & 13,308 & 1330,8 \\
\hline HP 7 Lambarene & 2,424 & 11,078 & 1107,8 \\
\hline HP 9 Oyem & 1,922 & 8,784 & 1190,9 \\
\hline HP 10 Oyem & 2,606 & 11,909 & 724,8 \\
\hline HPR 1/13/Loukoko & 1,586 & 7,248 & 583,1 \\
\hline HPR 2/13/ Loukoko & 1,276 & 5,831 & 978 \\
\hline HPR 3/13/ Loukoko & 2,140 & 9,780 & 711,5 \\
\hline HPR 4/13/ Loukoko & 1,557 & 7,115 & 1027,8 \\
\hline HPR 5/13/ Loukoko & 2,249 & 10,278 & 688,7 \\
\hline HPR 6/13/ Loukoko & 1,507 & 6,887 & 818,9 \\
\hline HPR 7/13/ Loukoko & 1,792 & 8,189 & 757,7 \\
\hline HPR 8/13/ Loukoko & 1,658 & 7,577 & 1110,5 \\
\hline HPR 9/13/ Loukoko & 2,43 & 11,105 & \\
\hline
\end{tabular}

As a whole, these results are similar to those found by Choo (1996) but higher than those of Sundram and Al (2003).

The carotenoids are very important functional compounds in the raw palm oil and their total content varies
$574,9 \mu \mathrm{g} / \mathrm{ml}$ with $1330,8 \mu \mathrm{g} / \mathrm{ml}$ for the samples of Gabon with an average of $1046,49 \mu \mathrm{g} / \mathrm{mL}$ and $583,1 \mu \mathrm{g} / \mathrm{mL}$ with $1110,5 \mu \mathrm{g} / \mathrm{ml}$ for the samples of Congo, with an average for the whole of $822,33 \mu \mathrm{g} / \mathrm{ml}$. 
The carotene rate of the palm oil $1,4,6,7$ and 8 of Loukoko (respectively $724,8 \mu \mathrm{g} / \mathrm{ml} ; 711,5 \mu \mathrm{g} / \mathrm{ml}$; $688,7 \mu \mathrm{g} / \mathrm{ml} ; 818,9 \mu \mathrm{g} / \mathrm{ml}$ and $757,7 \mu \mathrm{g} / \mathrm{ml})$ are similar to that brought back by Sundram (2003) and Tan (1986). The other samples of the two countries have rates of slightly high carotenoids; that could be related to the various agronomic, climatic, genetic factors (Hendson and Chai 1997; Hendson and Mohd 2005).

\section{Partial solidification}

An oil is defined as a liquid greasy substance at the natural state, and a grease, a greasy substance in a solid state. A liquid fraction and a solid fraction coexist in the palm oil, it is of this fact known as semi-solid. The relationship between the solid and the liquid is one of the criteria which enters the evaluation of the quality of oil, would be this only in an intuitive way on the level of the local consumer.

The refined palm oil must be completely colorless and limpid. Crude oil rich in vitamin has must be red and contain more liquid than of solid.
We evaluated, at the laboratory, the quantity of the solid deposited, after 4 days, starting from oils of reference which we used during the study. They are oils of references of the palm plantation of M'vouna, of the area of Franceville in the province of Haut-Ogooue (Gabon) and that of the Rural Campus of Loukoko (CRL) in Congo.

We followed the kinetics of formation of the solids starting from the liquid samples after extraction and during storage. The phenomenon observed seems to be random, it there a:

$\checkmark$ of oils in which the solid settles gradually at various speeds (figure 3);

$\checkmark$ of oils which take almost spontaneously masses some (figure 4);

$\checkmark$ of oils which take brutally in mass after a relatively long rest (figure 5);

$\checkmark$ of oils which remain completely liquid over the period of storage considered (figure 6).

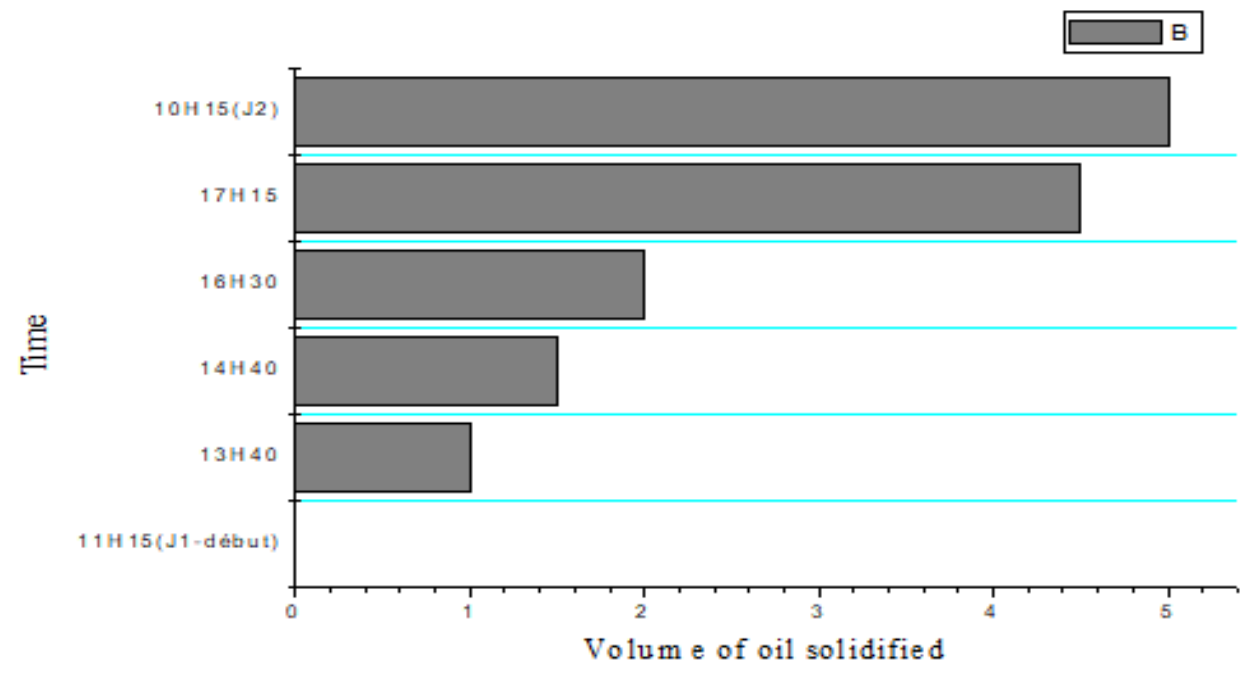

Fig.3: Progressive deposit of the solid in the palm oil (HPRIP. M'vouna)

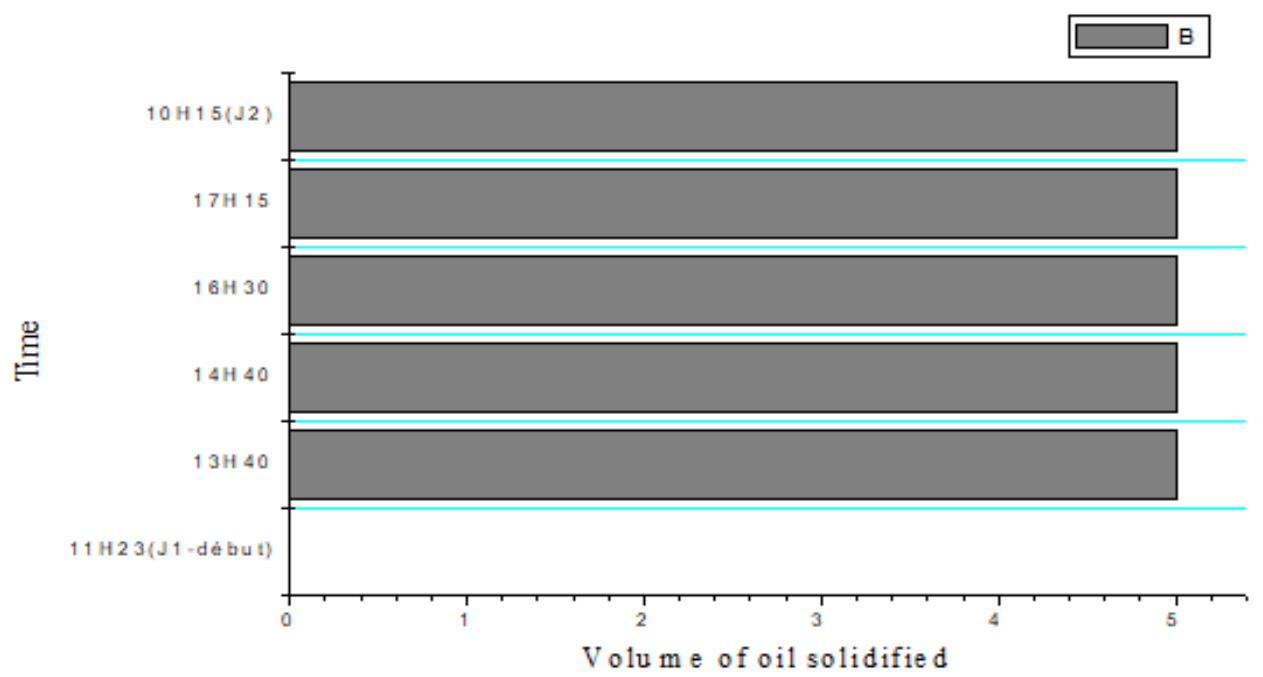

Fig.4: total deposit of the solid in the palm oil after a time HP3 P. M'vouna 


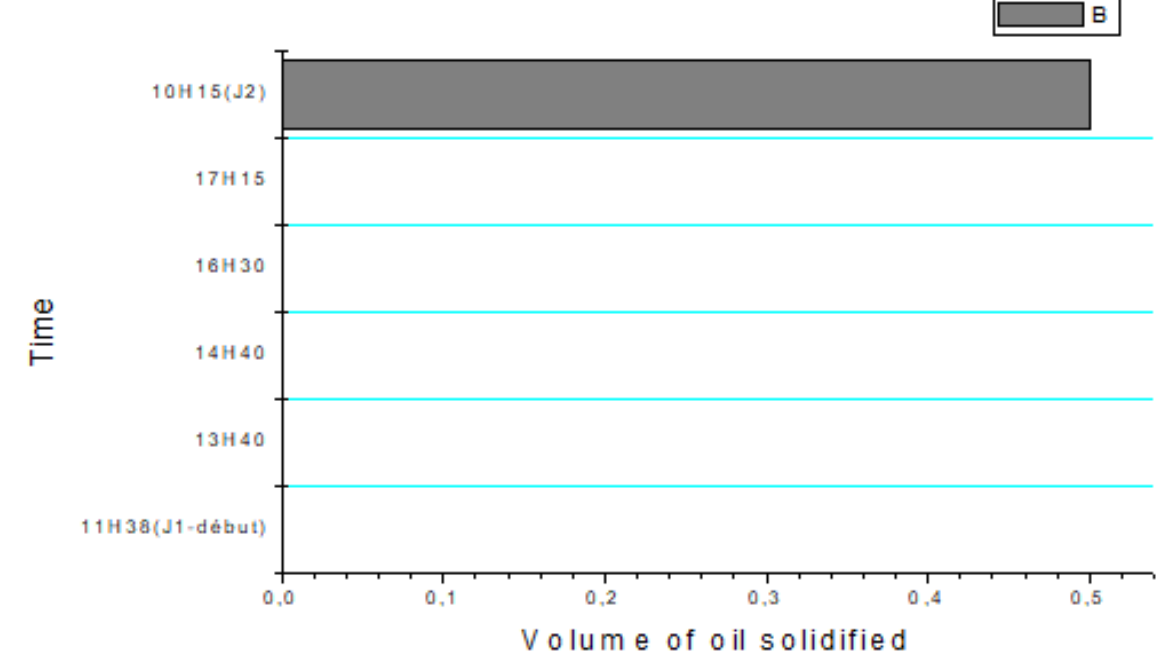

Fig.5: Deposit brutally masses some after a rest relatively long HP4 Lambarene

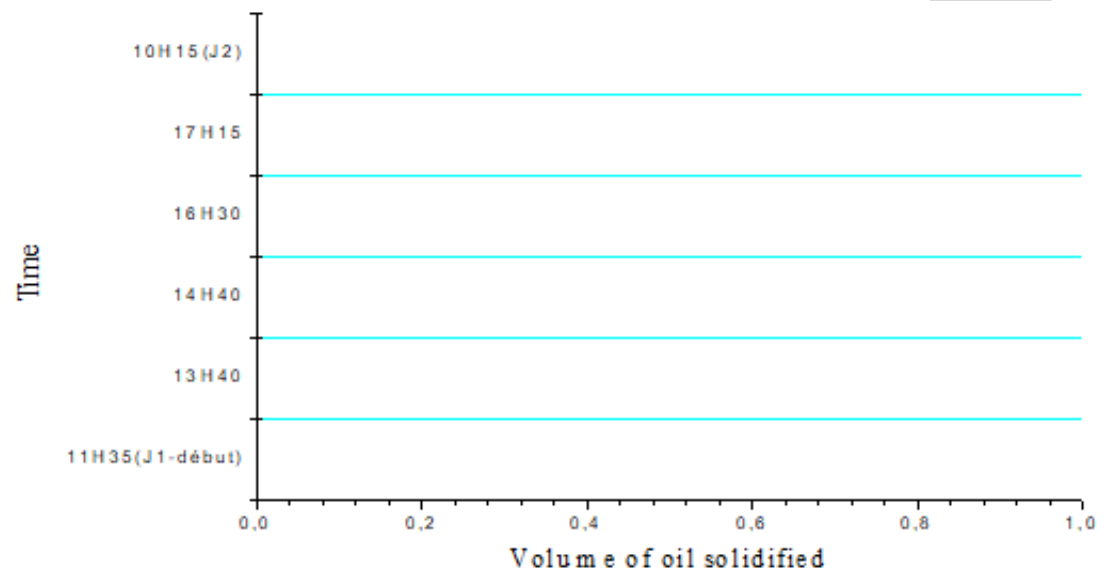

Fig.6: Absence of deposit over the period of storage considered HP 3 Lambarene

A work of qualitative evaluation of the content of solid (one month after extraction) of the various oils extracted the pilot unit of the Rural Campus of Loukoko (CRL), indicates a completely random behavior like illustrates it photograph 2.

We observed all the conceivable behaviors, as indicated higher for oils of Gabon, between completely solid oil with that completely liquid.

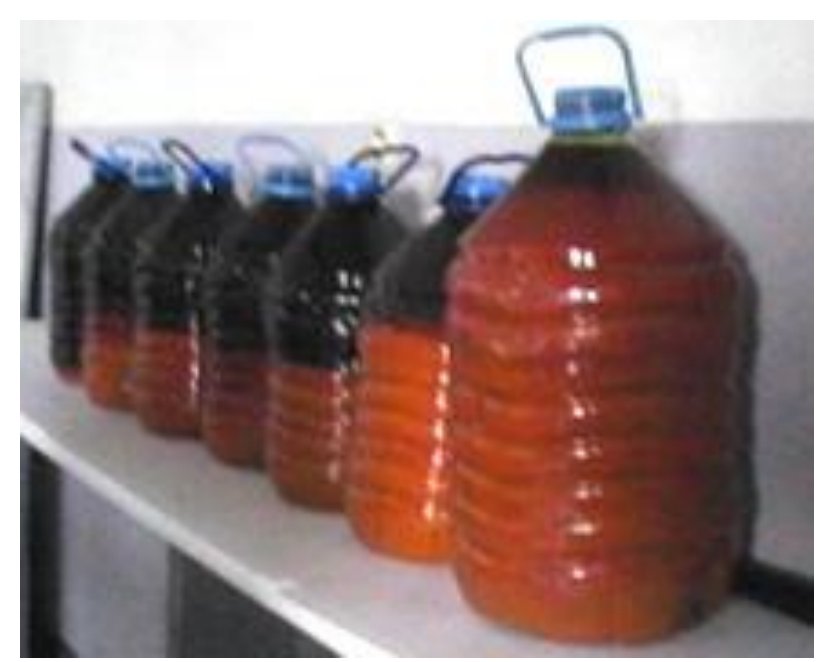

Photograph.2: Containers of 10L each one containing of oils resulting from different operations of extraction on the unit controls CRL (Congo). 
During precipitation partial of the raw palm oils of Gabon, three cases of figure ariseed. First case, the raw palm oil can be solidified gradually at the end of a certain time. Secondly, the raw palm oil can be solidified of only one blow in a very short time. And finally, the raw palm oil can not be solidified.

The raw palm oil is semi-solid, i.e. a liquid fraction and a solid fraction coexist. In the first case, the raw palm oil is solidified gradually and the solid fraction is lower than the liquid fraction then we can say than the palm oil presents less impurities than in the second case whose solid fraction is higher than the liquid fraction. In the third case, it on the other hand presents very few impurities and we can say thus that oil enough or much was filtered.

\section{Proportioning of polyphenols}

The antioxydant effects of polyphenols in the fruits, the wine, citrus fruits, the plants and certain oils as the olive oil were studied much but little work exist on the level of the raw palm oil. The effects of extracts polyphenolic of various varietal forms and various areas of the raw palm oil on oxidation were evaluated.

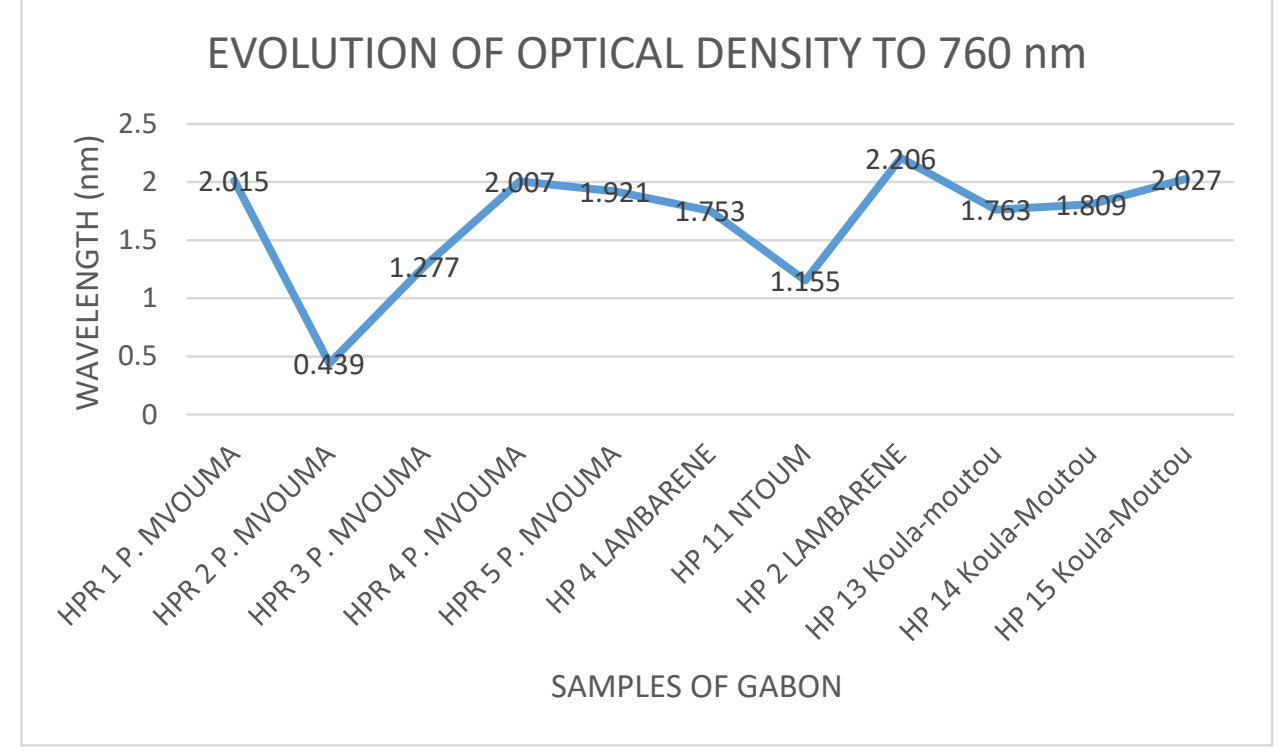

Fig.7: evolution of the optical density with $760 \mathrm{~nm}$ of the samples of Gabon

- Samples of Loukoko (2013)

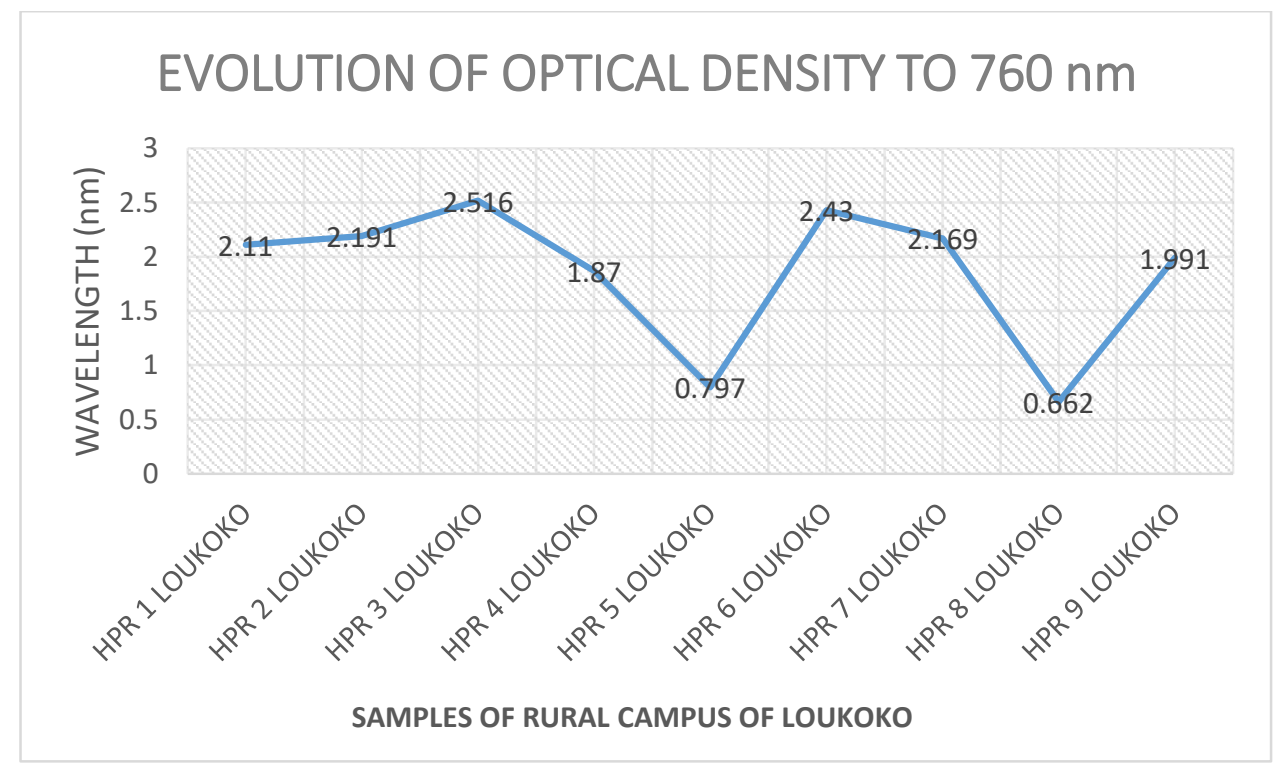

Fig.8: evolution of the optical density with $760 \mathrm{~nm}$ of the samples of Congo (Loukoko 2013)

\section{- Samples of Loukoko (2014)}


The reading of the OD has was made with the wavelength of $760 \mathrm{~nm}$.

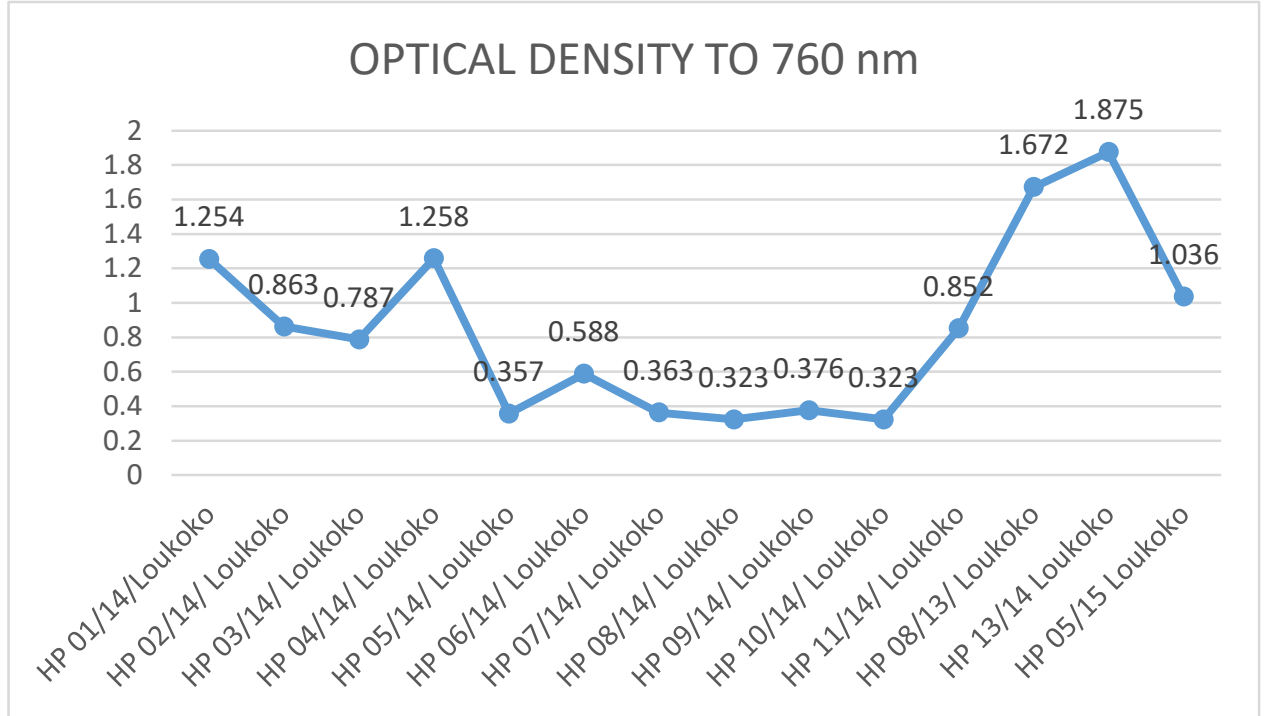

Fig.9: Evolution of the optical density with $760 \mathrm{~nm}$ of the samples of Congo (Loukoko 2014)

\section{Content total polyphenols}

The content polyphenols was given starting from the calibration curve of the gallic acid (see figure 10).

The calculation of the content polyphenol in the palm oil starting from OD with $450 \mathrm{~nm}$ was carried out in the following way:

$\mathrm{Y}=0,0012 \mathrm{x}-0,0004$

$\mathrm{X}=\frac{y+0,0004}{0,0012}$ with $\mathrm{X}$ : content polyphenol and there: represent the optical density

The content total polyphenols varies from 439 to 2516 $\mu \mathrm{g} / \mathrm{ml}$ (figure 11). Of all the analyzed samples, the sample of Congo (HPR 3 LOUKOKO) contains the maximum of phenolic compounds $(2516 \mu \mathrm{g} / \mathrm{ml})$. Minimum of 439 $\mu \mathrm{g} / \mathrm{ml}$, being obtained on sample HPR 2 P M'vouna (Gabon).

\begin{tabular}{|l|l|l|l|}
\hline $\mathrm{S}_{1}$ (solution & $0.2 \mathrm{~mL}$ oils & & \\
$1), \mathrm{C}_{1}, \mathrm{Q}_{1}$ & $0.2 \mathrm{~mL}$ water/methanol $\mathrm{CH}_{2} \mathrm{Cl}_{2}$ & Dilution & \\
\hline & $0.2 \mathrm{~mL}$ de $\mathrm{S} 1$ & $1 / 4$ & Dilution \\
$\mathrm{S}_{2}$ (solution & $0.8 \mathrm{~mL}$ reactive of & Dilution & \\
$2), \mathrm{C}_{2}, \mathrm{Q}_{2}$ & $\begin{array}{l}\text { Folin (diluted } 10 \text { times) } \\
1 \mathrm{~mL} \text { carbonate of } \mathrm{Na}\end{array}$ & $1 / 10$ & \\
& $(75 \mathrm{~g} / \mathrm{L})$ & & \\
& & & \\
\hline
\end{tabular}

C1, C2: concentrations of polyphenols in S1 and S2 in $\mu \mathrm{g} / \mathrm{mL}$ or $\mathrm{ppm}$

$\mathrm{Q} 1, \mathrm{Q} 2$ : quantities of polyphenols in $\mu \mathrm{g}$ in $\mathrm{S} 1$ and $\mathrm{S} 2$

Calibration curve

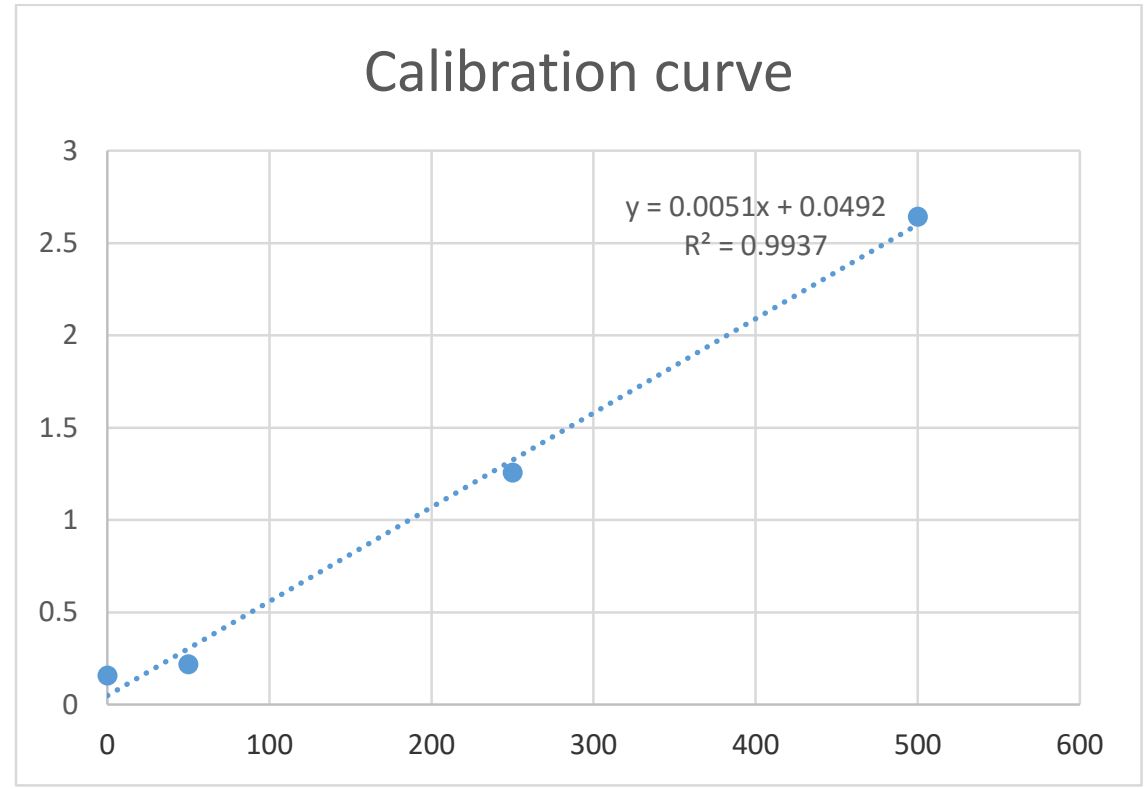

Fig.10: calibration curve of the gallic acid

$$
\begin{gathered}
\mathrm{Y}=0.0051 \mathrm{x}+0,0492\left(\mathrm{R}^{2}=0.9937\right) \\
\mathrm{OD}=0,0051 \mathrm{C}_{2}+0,0492(\mathrm{ppm})
\end{gathered}
$$




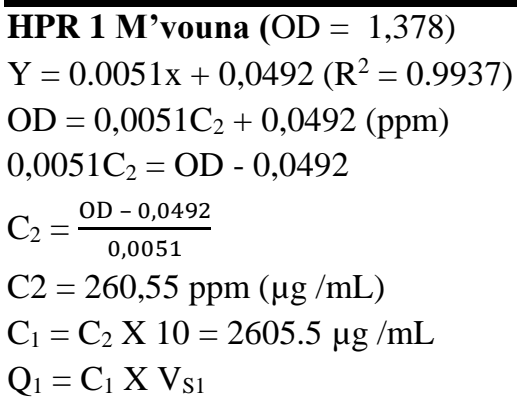

$\mathrm{Q}_{1}=2605,5 \times 0,8=2084,4$

$\mathrm{Q}_{1}\left(\mathrm{~V}_{\mathrm{S} 1}=0.8 \mathrm{ml}\right)=2084,4 \mu \mathrm{g}$

$2084,4 \mu \mathrm{g}$ polyphenol are containedin $0,2 \mathrm{ml}$ of starting oil

that is to say: $2084,4 \times 5 \mathrm{in} 1 \mathrm{ml}$

Content polyphenols in oil: $10422 \mu \mathrm{g} / \mathrm{mL}$ Is $10,4 \mathrm{mg} / \mathrm{ml}$

Appreciably equal to $10,4 \mathrm{mg} / \mathrm{g}$

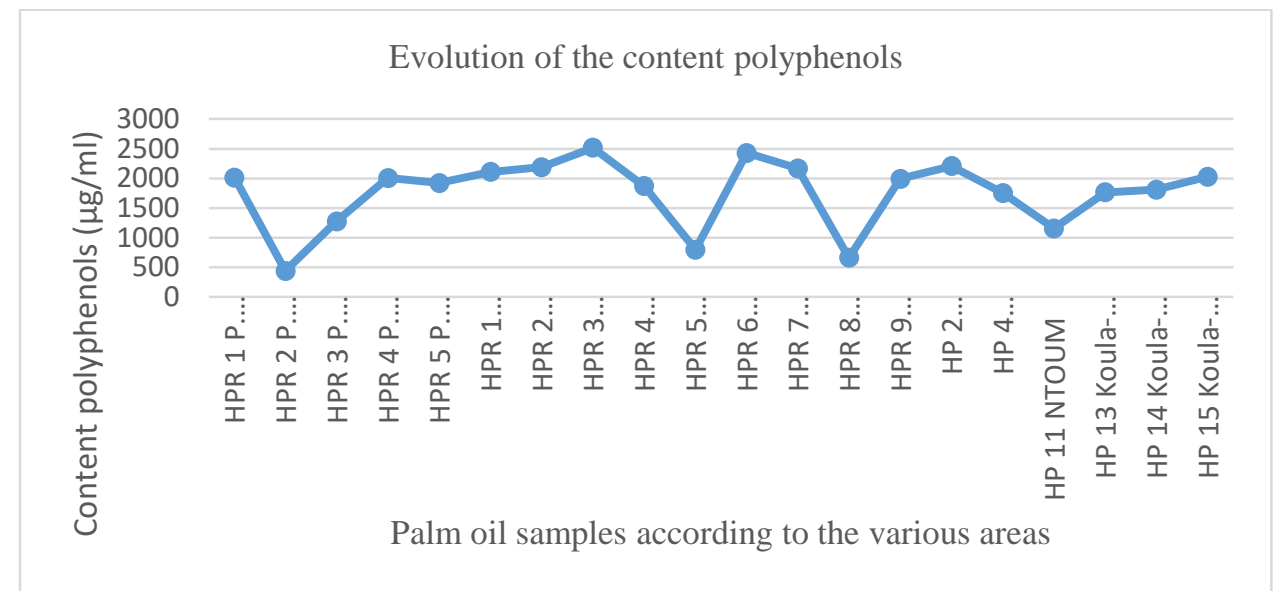

Fig.11: evolution of the content polyphenol of the various samples according to the areas

The contents total polyphenols were determined by the colorimetric method of Folin-Ciocalteu in the rough extracts ethanolic. The range of calibration was carried out starting from the gallic acid used like standard. The optical density was measured using a spectrophotometer of the type GENESYS 10 Bio (Photo 1).

The content total polyphenols varies from 3,1 to 14,6 $\mathrm{mg} / \mathrm{g}$ (figure 9) with a significant growth recorded for the various samples of Loukoko HPR $3 \mathrm{~L}$ and HPR $6 \mathrm{~L}$ (respectively $2516 \mathrm{mg} / \mathrm{g}$ and $2430 \mathrm{mg} / \mathrm{g}$ ). These results approach rather those found for the olive oil (Aguileraandal. 2005; Servile and al. 2003). The values found for our oils are as a whole higher than those reported by Aguilera and Al 2005.

The results presented to figure 11 , show that the total polyphenol contents of the analyzed palm oils strongly vary campaign with another.

Thus marketing year 2013/2014, was characterized by the highest contents total polyphenols (superior with 10422 $\mathrm{ppm}$ ). These contents similar to those are reported in work of Vossen (2007). The variations of the contents polyphenols observed can be due to the difference in degree of maturity of nuts before trituration (early harvest of nuts) but also depend on the varietal profile and the geographical area. It is the same for the fatty-acids and carotenoids.

Their high content in carotenoids, fatty-acid unsaturates and the strong content total polyphenols, make our different oils more beneficial as well in the nutritional plan as therapeutic. Indeed several work showed the undeniable role of polyphenols of the wine and the fruits, powerful antioxydant in the prevention of human pathologies, in particular of the cancerous tumors, the cardiovascular diseases, the inhibition of the oxidation of the LDL (Lan and Al 2007; Proteggente and Al 2002). These phenolic compounds correspond to a very broad range of chemical structures and are a good witness of the extraordinary capacity of biosynthesis of the plants, allowing their use in fields as varied as the agroalimentary one or pharmacology.

We noted a low variability of the various parameters: total fatty-acids, carotenoids and polyphenols in the raw palm oil consumed in Gabon and Congo. The various palm oil samples from Gabon, prove to be rich in saturated fattyacids, carotenoids and total polyphenols.

\section{CONCLUSION}

The raw palm oils produced in Gabon and Congo have considerable contents of carotene and natural polyphenols. Thus marketing year 2013/2014, was characterized by the highest contents total polyphenols (superior with $10422 \mathrm{ppm}$ ). The content polyphenols has a significant growth recorded for some samples of Loukoko (Congo) going up to $2516 \mathrm{mg} / \mathrm{g}$. The carotenoids are very important functional compounds in the raw palm oil and their total content is of 
$1046,49 \mu \mathrm{g} / \mathrm{mL}$ on average for the samples of Gabon and an average of $822,33 \mu \mathrm{g} / \mathrm{ml}$ for the samples of Congo. This strong rate of content carotenoids testifies to the perfect color orange red of the raw palm oil which indicates the presence of vitamin A. According to the conditions, the greasy substances are liquefied or solidified in varied and variable crystalline forms: it is what is called polymorphism. The whole of these data shows, contrary to many other vegetable fats, that the palm oil has many advantages: a strong consistency, a neutral taste, a relative thermal stability and a tartinability.

\section{REFERENCES}

[1] AFNOR (Association Française pour la Normalisation), (1981).Corps gras, graines oléagineuses, produits dérivés).Recueil des Normes Françaises, AFNOR, Paris (France). $2^{\mathrm{e}}$ Ed. p. 438.

[2] Anguilera J., Rodriguez-Vargas S., Prieto J.A. (2005). The HOG MAP Kinase pathway is required for introduction of methylglyoxal-responsible genes and determines methylglyoxal resistance in saccharomyces cerevisial. Mol microbial56 (1). p. 228-239.

[3] AOAC (Association of Official Analytical Chemists), (1999). Official Methods of Analysis. $16^{\text {th }}$ Ed. Ed. P. Cunniff, AOAC International, Maryland, MD (USA). p. 956.

[4] Benabid, H. (2009). Caractérisation de l'huile d'Olive Algérienne, Apports des méthodes chimiométriques. Thèse de Doctorat.Université Mentouri de Constantine (Algérie). p. 51-52.

[5] Codex Alimentarius (2005), Alinorm 01/17: Norme pour les huiles végétales portant un nom spécifique, Codex-Stan 210. p.14

[6] Codex Alimentarius (1995). Rapport de la quatorzième session du comité du codex sur les graisses et les huiles. Alinorm 95/17.21 ${ }^{\text {ème }}$ Session. Londres, Royaume Uni. p. 9-16

[7] Davis AR., Fish W.M., Perkings Veazie P. (2008/2009). A rapid spectrophotometric method to determine beta-carotene content in Cucumis melo germplasm. Cucurbit genetic cooperative Report 31/32. p. 5-7

[8] Decker, E. A. (1995). The role of phenolics, conjugated linoleic acid, carnosine, and pyrroloquinoline quinone as non-essential dietary antioxidants. Nutr Rev. 53. p. 49-58.

[9] FAO/OMS (1977). Rôle des graisses et huiles alimentaires en nutrition humaine. Rapport d'une commission mixte d'experts. Rome (Italie). p. 105
[10] Hartmut, K. et Lichtnetharler, (1987). Chlorophylls and Carotenoids: Pigments of photosynthetic. Methods in Enzymology.148, pp. 350-382

[11] Helmy, E. H. (1990). Studies on the pigments of some citrus, prune and cucurbit seed oils when processed with or without cotton seed oil.J. Amer. Oils Chem. Soc.. 67(6). p .376-380.

[12] Hendson I.E., Mohd H.H. (2005). The influence of climatic conditions on gas and energy exchanges above a young oil palm stand in north Kedah, Malaysia. Journal of Oil Palm Research, 17: 73-91.

[13] Hendson IE., Chai SH. (1997). Analysis of oil palm productivity. II. Biomass, distribution, productivity and turnover of the root system. Elaeis, 9:78-92.

[14] IUPAC (International Union of Pure and Applied Chemistry). (1979). Méthodes d'analyses des matières grasses et dérivés. $6^{\text {ème }}$ Ed. Lavoisier Tec et Doc. Paris (France) p 190.

[15]Lan S., Jun-Jie Y., Denys C., Kequan Z., Jerey M., Liangli (Lucy) Y. (2007). Total phenolic contents, chelating capacities, and radicalscavenging properties of black peppercorn, nutmeg, rosehip, cinnamon and oregano leaf. Food Chemistry, 100. 990-997.

[16] Lecerf, J. M. (2013). L'huile de palme: aspects nutritionnels et métaboliques. Rôle sur le risque cardiovasculaire.OCL. 20 (3). p. 147 - 159.

[17] Proteggente A. R., Pannala A. S., Paganga G., Van Buren L., Wagner E., Wiseman S., Van De Put F., Dacombe C., Rice-Evans C.A. (2002). The antioxidant activity of regularly consumed fruit and vegetables reflects their phenolic and vitamin C composition. Free Radical Research. 36 (2): 217-33.

[18] Serville M. N., Demanez L., Demanez J. P. (2003). Acta Oto-rhino-laryngologica.Belgica. 58 (1). p.5359.

[19] Silou, Th. Biyoko, S., Heron, S., Tchapla, A., Maloumbi, M.G. (2004).Caractéristiques physicochimiques et potentialités technologiques des amandes d'Irvingia gabonensis, Rivist. Ital. della sostanze grasse, 81. p.49- 57.

[20] Sundram K., Sambanthamurthi R., Tan YA. (2003). Palm fruit chemistry and nutrition. Asia Pacific Journal of Clinical Nutrition, 12 (3): 355-62.

[21] Tan, B. (1988). Oil Palm / Palm oil Conf : Tech. Progress and Prospect, A.S.H. Edition Ong, PORIM Press, Kuala Lumpur, Malaysia, p. 370.

[22] Visioli, F. Bellomo, G. Montedoro, G. et Galli, C. (1995).Low density lipoprotein oxidation is 
inhibited in vitro by olive oil constituents. Atherosclerosis. 117. p. 25-32.

[23] Vossen, P.-M.(2007). International olive oil council trade standard for olive oil. Organic Olive Production Manual. ANR Publications.105). p 2324. 